\title{
Recognition of cigarette brand names and logos by primary schoolchildren in Ankara, Turkey
}

\author{
Salih Emri, Tülay Bağcı, Yalçın Karakoca, Enis Barıș
}

Department of Chest Diseases, School of Medicine, Hacettepe University, Ankara, Turkey

S Emri

Y Karakoca

Department of Community Medicine T Bağc1

Strategies and Policies for Healthy Societies Programs Branch, International

Development Research Center, Canada

E Barıș

Correspondence to: Dr S Emri, Department of Chest Diseases, School of Medicine, Hacettepe University, Ankara, Turkey 06100;

se06-k@tr-net.net.tr

Table 1 Cigarette smoking status, by age and gender

\begin{tabular}{|c|c|c|c|c|c|}
\hline \multirow[b]{2}{*}{ Age (years) } & \multicolumn{2}{|l|}{ Boys } & \multicolumn{2}{|l|}{ Girls } & \multirow[b]{2}{*}{ Total $n$} \\
\hline & $\begin{array}{l}\text { Never-smoker } \\
n(\%)^{\star}\end{array}$ & $\begin{array}{l}\text { Ever-smoker } \\
n(\%)^{\star}\end{array}$ & $\begin{array}{l}\text { Never-smoker } \\
n(\%)^{\star}\end{array}$ & $\begin{array}{l}\text { Ever-smoker } \\
n(\%)^{\star}\end{array}$ & \\
\hline$\leqslant 8 \dagger$ & $68(77)$ & $20(23)$ & 79 (83) & $16(17)$ & 183 \\
\hline 9 & $134(87)$ & $20(13)$ & $129(93)$ & $10(7)$ & 293 \\
\hline 10 & $138(86)$ & $22(14)$ & $114(92)$ & $10(8)$ & 284 \\
\hline$\geqslant 11$ & $149(90)$ & 17 (10) & $99(94)$ & $6(6)$ & 271 \\
\hline Total & $489(86)$ & $79(14) \ddagger$ & $421(91)$ & $42(9)$ & 1031 \\
\hline
\end{tabular}

*Row percentages.

$t \chi^{2}=14.5, \mathrm{p}<0.05, \leqslant 8$ years of age $v s \geqslant 9$ years of age.

$\ddagger \chi^{2}=5.79, \mathrm{p}<0.05$ (boys vs girls). $11.7 \%$ overall $(13.9 \%$ among boys and $9.1 \%$ among girls; $p<0.05)$. Children aged eight years or less had a higher prevalence of ever-smoking $(19.6 \%)$ than older children $(p<0.002)$. Ever-smoking prevalence did not differ significantly across the three school districts. Ever-smoking prevalence was higher among children with at least one parent who smoked $(15.3 \%)$ than among those whose parents did not $(4.8 \%)$ $(\mathrm{p}<0.001)$. Brand recognition rates ranged from $58.1 \%$ for Chee-tos (a food product) to $95.2 \%$ for Samsun (a Turkish cigarette brand). Recognition rates for cigarette brand names and logos were $95.2 \%$ and $80.8 \%$, respectively, for Samsun; $84.0 \%$ and $90.5 \%$, respectively, for Camel; and $92.1 \%$ and $69.5 \%$, respectively, for Marlboro. The Camel logo and the Samsun and Marlboro brand names were

\begin{abstract}
Objective-To assess the smoking behaviour of primary schoolchildren and their ability to recognise brand names and logos of widely advertised cigarettes, compared with other commercial products intended for children.
\end{abstract}

Design-Cross-sectional survey in classroom settings using a questionnaire designed to measure attitudes towards smoking and the recognition of brand names and logos for 16 food, beverage, cigarette, and toothpaste products.

Setting-Ankara, Turkey.

Subjects-1093 children $(54.6 \%$ boys, $44.4 \%$ girls) aged 7-13 years (mean $=10$, SD = 1), from grades 2-5. The student sample was taken from three primary schools-one school in each of three residential districts representing high, middle, and low income populations.

Main outcome measures-Prevalence of ever-smoking, recognition of brand names and logos.

Results-Prevalence of ever-smoking was 
Table 2 Brand and logo recognition rates, by gender

\begin{tabular}{|c|c|c|c|c|}
\hline & \multicolumn{2}{|c|}{ Boys } & \multicolumn{2}{|c|}{ Girls } \\
\hline & $n$ & $\%$ & $n$ & $\%$ \\
\hline \multicolumn{5}{|l|}{ Foods } \\
\hline Milka brand & 478 & 89.1 & 862 & 88.0 \\
\hline Milka logo & 382 & $71.0^{\star}$ & 276 & $61.9^{\star}$ \\
\hline Chee-tos brand & 318 & 58.7 & 244 & 57.2 \\
\hline Uzay logo & 480 & $87.4^{\star}$ & 354 & $80.9^{\star}$ \\
\hline McDonald's logo & 377 & 67.3 & 279 & 63.4 \\
\hline \multicolumn{5}{|l|}{ Cigarettes } \\
\hline Samsun brand & 519 & 96.4 & 376 & 93.9 \\
\hline Samsun logo & 460 & $83.4^{\star}$ & 355 & $78.2^{\star}$ \\
\hline Camel brand & 482 & $89.8^{\star}$ & 322 & $77.6^{\star}$ \\
\hline Camel logo & 508 & $92.7^{\star}$ & 392 & $88.5^{\star}$ \\
\hline Marlboro brand & 492 & 92.7 & 402 & 91.9 \\
\hline Marlbora logo & 396 & $73.2^{\star}$ & 287 & $65.6^{\star}$ \\
\hline \multicolumn{5}{|l|}{ Drinks } \\
\hline Tuborg brand & 461 & $87.2^{\star}$ & 316 & $73.5^{\star}$ \\
\hline Tuborg logo & 458 & $84.5^{\star}$ & 319 & $73.7^{\star}$ \\
\hline Coke logo & 495 & $89.0^{\star}$ & 374 & $81.4^{\star}$ \\
\hline \multicolumn{5}{|l|}{ Others } \\
\hline Colgate brand & 413 & 79.1 & 307 & 74.4 \\
\hline Colgate logo & 465 & 85.0 & 363 & 82.3 \\
\hline
\end{tabular}

which is located in the city of Akhisar in Western Turkey.

In Turkey, smoking prevalence among the adult population (above 15 years of age) is $62.8 \%$ in men and $24.8 \%$ in women, ${ }^{5}$ higher than the average prevalence in developing and developed countries. The age of smoking initiation is considerably lower in Turkey. About $13.2 \%$ of those aged $15-18$ years are smokers. ${ }^{5}$ Although reliable epidemiological data are lacking, a steady increase in lung cancer mortality was reported in both sexes from 1965 to 1990 . Forty per cent of cancer deaths in men and $15 \%$ in women were due to lung cancer in $1992 .{ }^{6}$ These figures make tobacco an important public health issue in Turkey.

Despite the high prevalence of smoking and the health-related economic burden, until November 1996 there had been no comprehensive legislation to combat the overwhelming smoking epidemic in Turkey. Both children and adults were exposed to tobacco advertising. Cigarettes were advertised mainly through billboards (for example, those featuring the Marlboro cowboy), print media (posters, magazines), broadcast media (movies, private television programmes supported by Parliament Cinema Club, jazz concerts organised as part of the annual "Parliament Jazz Festival"), and promotions in school canteens. Children have been shown to recall, admire, discuss, and generally relate to cigarette advertising in the same manner as do adults. $^{7}$

This study was conducted to assess the extent to which the above factors influence smoking behaviour among young people in

Table 3 Factors affecting recognition of cigarette brand names - adjusted odds ratios and $95 \%$ confidence intervals (CI)

\begin{tabular}{lllll}
\hline Category/variable & All correct & $95 \%$ CI & $\begin{array}{l}2 \text { of } 3 \\
\text { correct }\end{array}$ & $95 \%$ CI \\
\hline Age (per year) & 1.73 & $1.52-1.99$ & 1.70 & $1.44-2.01$ \\
Gender (male) & 1.79 & $1.34-2.40$ & 0.89 & $0.62-1.28$ \\
Smoking (ever) & 0.78 & $0.50-1.22$ & 0.84 & $0.50-1.42$ \\
Parents' smoking (ever) & 0.98 & $0.86-1.12$ & 1.0 & $0.31-1.18$ \\
School districts & & & & \\
$\quad$ Middle income & 4.87 & $3.39-6.95$ & 4.61 & $3.06-6.95$ \\
$\quad$ High income & 7.10 & $4.82-10.44$ & 7.09 & $4.46-11.0$ \\
\hline
\end{tabular}

Turkey (before adoption of tobacco control legislation) and their ability to recognise brand names and logos of widely advertised cigarettes, compared with other commercial products intended for children.

\section{Methods}

STUDY POPULATION

The study was performed in January and February 1996, before smoking legislation went into effect on 7 November $1996 .{ }^{8}$ The sample population consisted of 1093 children, among whom 579 (55.6\%) were boys and 485 $(44.4 \%)$ were girls. The children were in grades $2-5$, and had a mean age of 10 years (range $=7-13, \mathrm{SD}=1$ ). The ages corresponding to these grades were: $7-8$ years old, grade 2 ; 9 years old, grade $3 ; 10$ years old, grade 4 ; and 11-13 years old, grade 5 .

The study sample was drawn from three primary schools - one school in each of three different residential districts representing the three socioeconomic classes (high, middle, and low income). The catchment area of the low income district was one of the squatter regions of Ankara (Hüseyin Gazi); that of the middle income district was located in the urban area of Ankara (Bahçelievler), and the primary school representing the high income district was located in our university campus (Beytepe). The first two were public schools where registration is limited to inhabitants of the surrounding neighbourhood, while the third is a private school. The study group consisted of all students who attended class at the time of the survey.

\section{STUDY DESIGN}

This study used a cross-sectional, questionnaire-based survey. After students were informed of the anonymity of the survey, the questionnaire was administered to them in their classrooms under the supervision of a researcher and their teachers. The questionnaire was a translation and modification of a previously used questionnaire, ${ }^{9}$ which included multiple-choice questions related to current smoking status; self-purchase of cigarettes in the week before administration of the questionnaire; knowledge of and attitudes toward the smoking behaviour of their parents, teachers, and the public; and parents' smoking status.

The children were also asked to classify nine logos and seven brand names of different commercial products: domestic and foreign cigarettes, toothpaste, food, beer, and soft drinks. The brand names were Milka (a food), Samsun (a Turkish cigarette brand), Chee-tos (a food), Camel, Colgate, Tuborg (a beer), and Marlboro. The advertising logos shown to the children-which represented Tuborg, Marlboro (red chevron), McDonald's, Camel (traditional camel on the cigarette package), Colgate, Uzay (Turkish logo representing Chee-tos), Coca Cola (Coke), Milka, and Samsun Illustrations - are reproduced in the appendix.

Responses to these brand names and logos were classified into five categories according to 
Table 4 Brand and logo recognition rates, by smoking status

\begin{tabular}{|c|c|c|c|c|c|c|}
\hline & \multicolumn{2}{|c|}{ Never-smokers } & \multicolumn{2}{|c|}{ Ever-smokers } & \multicolumn{2}{|c|}{ Unadjusted } \\
\hline & $n$ & $\%$ & $n$ & $\%$ & $O R$ & $95 \% C I$ \\
\hline \multicolumn{7}{|l|}{ Brands } \\
\hline Milka & 805 & 88.8 & 91 & 84.6 & 0.69 & $0.36-1.34$ \\
\hline Samsun & 820 & 95.2 & 98 & 95.9 & 1.17 & $0.39-3.96$ \\
\hline Chee-tos & 805 & 58.4 & 100 & 56.0 & 0.91 & $0.58-1.41$ \\
\hline Camel & 795 & 84.4 & 97 & 80.4 & 0.76 & $0.43-1.35$ \\
\hline Colgate & 790 & 78.5 & 92 & 65.2 & 0.51 & $0.32-0.84$ \\
\hline Tuborg & 802 & 81.2 & 91 & 83.5 & 1.18 & $0.64-2.20$ \\
\hline Marlboro & 799 & 92.1 & 99 & 88.9 & 0.68 & $0.33-1.43$ \\
\hline \multicolumn{7}{|l|}{ Logos } \\
\hline Tuborg & 802 & 79.8 & 91 & 79.1 & 0.96 & $0.55-1.70$ \\
\hline Marlboro & 799 & 68.6 & 99 & 75.8 & 1.43 & $0.86-2.39$ \\
\hline McDonald's & 836 & 66.0 & 107 & 58.9 & 0.74 & $0.48-1.13$ \\
\hline Camel & 795 & 91.4 & 97 & 85.6 & 0.57 & $0.30-1.11$ \\
\hline Colgate & 790 & 84.9 & 92 & 72.8 & 0.48 & $0.28-0.81$ \\
\hline Uzay & 805 & 84.5 & 100 & 85.0 & 1.04 & $0.57-1.95$ \\
\hline Coke & 836 & 85.5 & 107 & 85.9 & 1.04 & $0.56-1.93$ \\
\hline Milka & 805 & 66.2 & 91 & 70.3 & 1.21 & $0.74-2.00$ \\
\hline Samsun & 820 & 81.2 & 98 & 81.6 & 1.03 & $0.58-1.83$ \\
\hline
\end{tabular}

$\mathrm{OR}=$ odds ratios $\mathrm{CI}=$ confidence intervals.

the products they represented: food, cigarette, drink, other, and not known. All the brand names tested were represented by their coloured logos. The sample logos were reproduced from the packages of the products in question. The logos representing Camel,
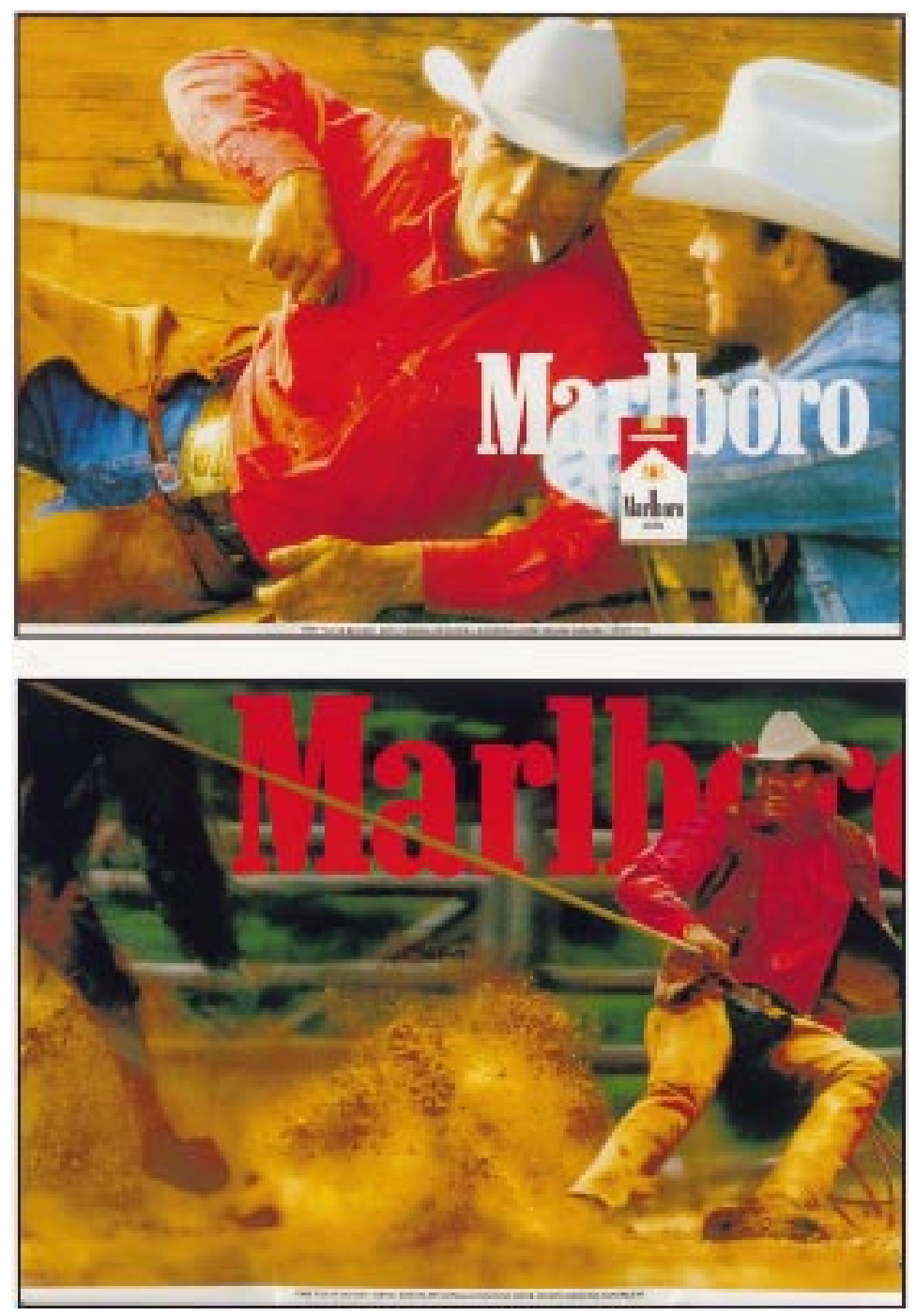

Figure 1 Examples of tobacco advertisements in Turkey before passage of legislation in 1996 banning tobacco advertising and promotion.
Marlboro, Samsun, Milka, Coca Cola, and Chee-tos did not contain the brand names of the products. The advertised brand names and the logos were given in print form in the second page of the questionnaire (opposite). Pilot testing of the questionnaire was done to ensure that questions were clear, and to verify the validity and reliability of self-reported cigarette smoking.

ANALYSIS

Smoking status of the children was determined by one of the following four possible answers, as in a previous study': (1) never smoked; (2) tried smoking once or a few times; (3) smokes sometimes, less than one cigarette a week; and (4) smokes one or more cigarettes a week. The child's smoking status was defined as never-smoker (answer 1) or ever-smoker (answer 2, 3, or 4). Despite the availability of disaggregated data for the four defined smoking-status categories, the analysis was dichotomous (never/ever) to render it comparable with similar studies-for example, one in China. ${ }^{9}$

Brand identification was assessed by summing up all the correct answers, including the identification of brand names and logos in each product category.

The overall analysis was conducted using the SPSS statistical software. $\chi^{2}$ and variance analyses were used to determine the significance between the groups. Logistic regression analysis was used to determine the importance of factors affecting recognition of cigarette brand names. Statistical significance was defined as $\mathrm{p}<0.05$.

\section{Results}

In the group of 1093 students, 1031 (94.4\%) completed the questionnaires ( 62 who failed to indicate their gender and smoking status were excluded). Prevalence of ever-smoking was $11.7 \%$ overall $(13.9 \%$ among boys and $9.1 \%$ among girls; $\chi^{2}=5.76, \mathrm{p}<0.05$ ) (table 1$)$. The highest prevalence of ever-smoking (19.6\%, $36 / 183$ ) was observed in the age group of eight years or less (most of whom were in grade 2). There was no significant difference in smoking prevalence across the three residential districts included in the study $\left(\chi^{2}=2.69, \mathrm{p}>0.05\right)$; in other words, socioeconomic class did not appear to affect smoking prevalence.

Twenty-four per cent (245/1022) of the students reported buying cigarettes during the week preceding the study. Ever-smoking children $(49.1 \%, 59 / 120)$ were more likely to have bought cigarettes than never-smokers $(20.6 \%, 186 / 902)\left(\chi^{2}=47.3, \mathrm{p}<0.0001\right)$.

Sixty-sixty per cent $(710 / 1080)$ of respondents reported that at least one of their parents was a smoker. Smoking was more prevalent among children with a parent who had smoked $(15.3 \%)$ as compared with children of non-smoking parents $(4.8 \%) \quad\left(\chi^{2}=24.67\right.$, $\mathrm{p}<0.0001)$. Smoking was less common among children whose fathers were healthcare practitioners $(2.5 \%, 1 / 40)$ in comparison with those whose fathers were self-employed, officials, or manual workers $\left(\chi^{2}=7.88, \mathrm{p}<0.05\right)$. 


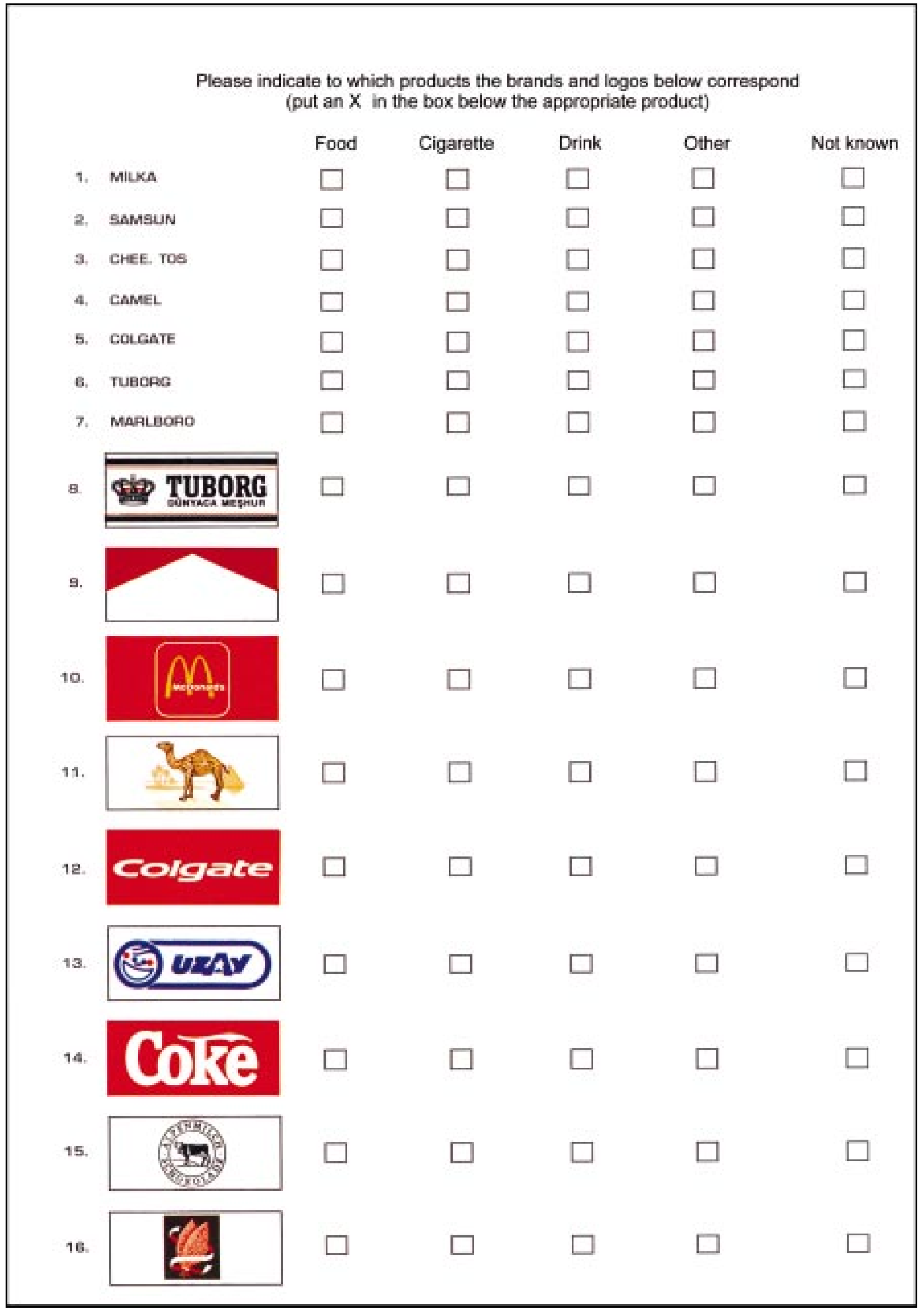

Illustrations shown to the children as the second part of the questionnaire. 


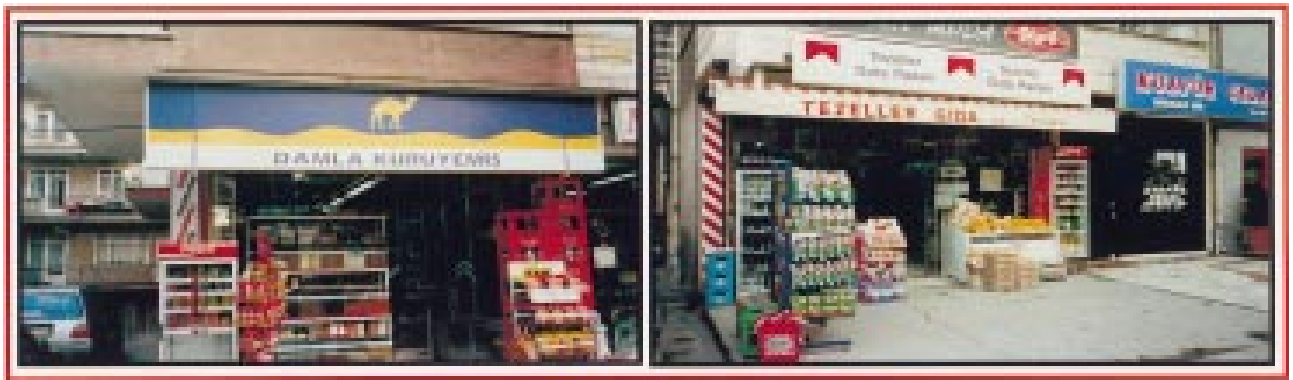

Figure 2 Store front signs for Camel and Marlboro cigarettes displayed after adoption of legislation in 1996 banning tobacco advertising and promotion.

There was no significant difference in smoking behaviour between children whose parents smoked domestic cigarettes and those whose parents smoked foreign brands $\left(\chi^{2}=3.79\right.$, $\mathrm{p}>0.05)$. Of the 118 ever-smoking children, 89 (75.4\%) were against their parents' smoking.

Most children (68.6\%) stated that they had not been taught in school about the adverse health effects of smoking. A majority $(81.2 \%)$ believed that smoking should be prohibited in public places, and this opinion did not differ significantly according to smoking status.
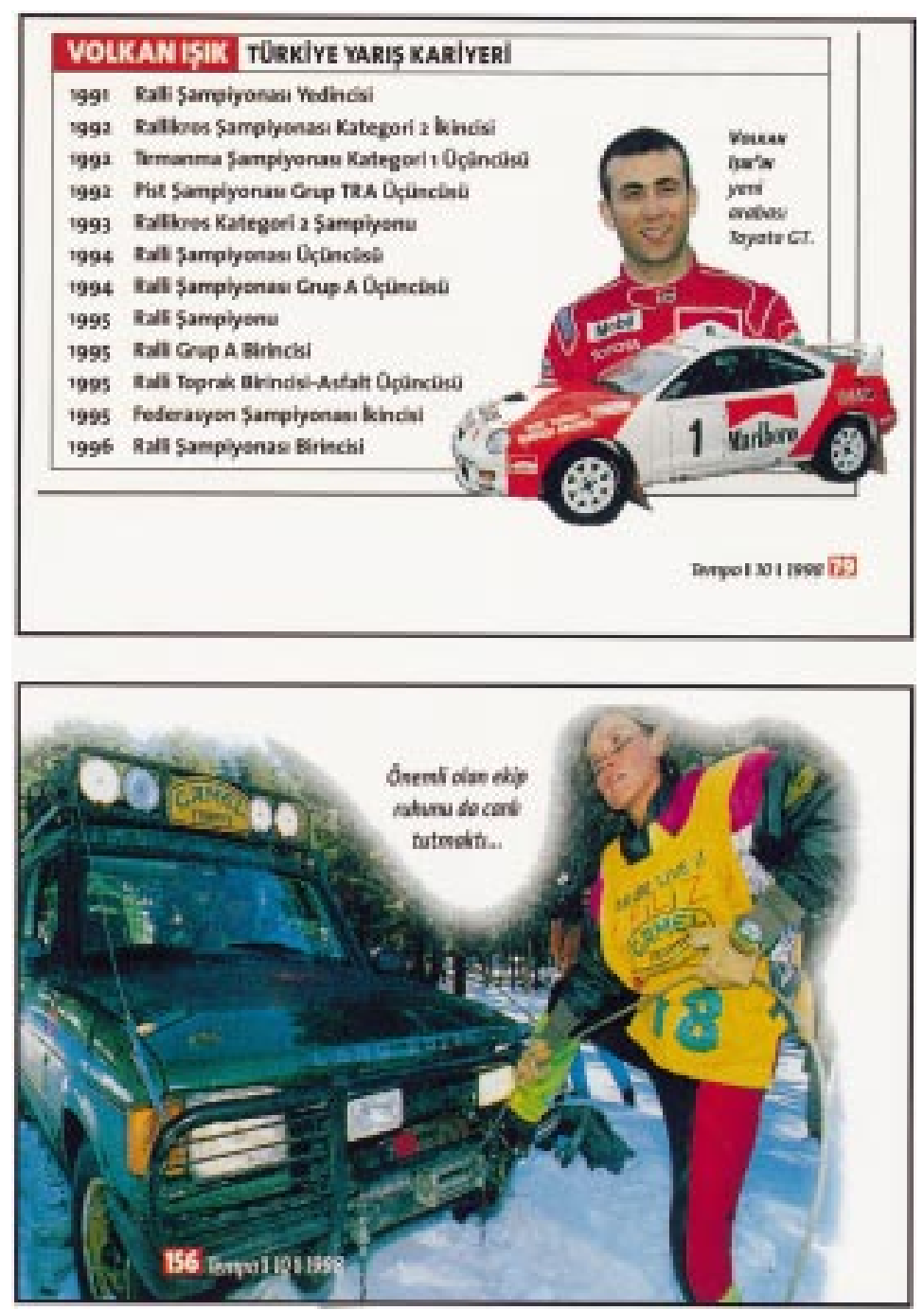

Figure 3 Indirect advertising appearing after the ban on tobacco advertising, in the form of news stories about the Marlboro-sponsored Turkish rally team and the Camel Adventure Tour.
The total mean scores for recognition of all brand names and logos differed significantly by sex (11.2 for boys vs 10.4 for girls, $F=11.83$, $\mathrm{p}<0.001)$. Brand recognition ranged from $58.1 \%$ for Chee-tos (a food) to $95.2 \%$ for Samsun (a domestic cigarette brand) (table 2). Recognition rates for cigarette brand names and logos were $95.2 \%$ and $80.8 \%$, respectively, for Samsun; $84.0 \%$ and $90.5 \%$, respectively, for Camel; and $92.1 \%$ and $69.5 \%$, respectively, for Marlboro. The Camel logo and the Samsun and Marlboro brand names were the most highly recognised of all product logos and brand names tested (table 2).

After adjustment for age, gender, parental smoking, and residential district, higher brand recognition rates for cigarettes were strongly associated with older age (odds ratio $(\mathrm{OR})=$ $1.73 ; 95 \%$ confidence interval $(\mathrm{CI})=1.52$ to $1.99)$ and male gender $(\mathrm{OR}=1.79 ; 95 \% \mathrm{CI}=$ 1.34 to 2.40 ). Pupils from the middle and high income districts were more likely to recognise all cigarette brands $(\mathrm{OR}=4.87 \quad(95 \%$ $\mathrm{CI}=3.39$ to 6.95$)$ for middle income; $\mathrm{OR}=$ $7.10(95 \% \mathrm{CI}=4.82$ to 10.44$)$ for high income) (table 3).

Never-smokers were more likely than ever-smokers to recognise the brand name and logo of Colgate. There were no significant differences in recognition rate for the other products according to smoking status (table 4).

\section{Discussion}

We found a prevalence of ever-smoking of $11.7 \%$ among the children in this study (13.9\% in boys and $9.1 \%$ in girls). Similar rates have been reported for the same age group in earlier studies. In 1983, smoking prevalence among secondary school and high school students in Ankara was reported to be $9 \%$ and $38 \%$, respectively. ${ }^{10}$ In 1990 , Tümerdem et al ${ }^{11}$ reported a smoking prevalence of $10 \%$ in boys and $7 \%$ in girls in primary school (grades 3-5) in the outskirts of Istanbul.

These figures are similar to those reported by Peters et $a l^{9}$ for Hong Kong; they found the prevalence of ever-smoking to be $11 \%$ (15\% in boys and $7 \%$ in girls) for children of the same age group. In a study conducted in England in 1994, the prevalence of regular smoking among children aged 11 to 15 was $12 \%(10 \%$ in boys and $13 \%$ in girls); however, the prevalence of ever-smoking was much higher- $47 \%$ in boys and $48 \%$ in girls. ${ }^{12}$ 
If a comparison is made with industrialised countries, the situation in Turkey would correspond to the first cycle of the S-shaped diffusion curve. ${ }^{13}$ This means that none of the groups (men, women, boys, or girls) has entered the second cycle-that is, adopting non-smoking.

In our study, the male-to-female ratio for smoking prevalence was 1.5. A 1988 study in Istanbul, in an urban population over 18 years of age, found a smoking prevalence of $54.5 \%$ for men and $32.9 \%$ for women (male-tofemale ratio $=1.6) .{ }^{14}$ These figures suggest that women in large cities are more likely to smoke. Bilir et al ${ }^{15}$ reported an even higher prevalence of current smoking among women in Ankara$37 \%$. We believe that introduction of Westernstyle cigarettes may have resulted in a higher smoking rate among women.

The tobacco industry supports cultural and sporting activities to stimulate smoking among adolescents and children, especially in developing countries. This has also been the case in Turkey. Before the adoption of national tobacco control legislation in $1996,{ }^{8}$ tobacco advertising was permitted freely in Turkey with the exception of national radio and television channels (figure 1). Nowadays the most common types of marketing by Philip Morris and RJ Reynolds are price announcements for cigarettes in newspapers, and illegal cigarette promotions in bars and restaurants. In addition, indirect advertising occurs on store fronts and through sponsorships (figures 2 and 3).

Despite the fact that of every 100 packets of cigarettes sold in Turkey, one is Camel and six are Marlboro, while 20 are Samsun (which has been taken over by BAT), the recognition rate for Camel and Marlboro is almost as high as that of the domestic brand. This suggests that the transnational companies are more successful in their advertising. Despite the fact that Camel's "Old Joe" cartoon character has not been promoted heavily in Turkey, the Camel logo had the highest recognition rate among the tested cigarettes logos $(90.5 \%)$. This figure approaches the $93.6 \%$ one reported for the United States. ${ }^{16}$

Our study provides evidence that the smoking status of parents has an effect on the smoking behaviour of their children, consistent with the findings of other investigators. ${ }^{13}{ }^{17}$

During the week preceding our survey, 24\% of all students reported having bought cigarettes. This proportion is higher than the prevalence of ever-smoking $(11.7 \%)$ in our study sample. The difference is likely due to the fact that children (including non-smokers) commonly buy cigarettes for their parents or teachers. Because the sale of tobacco products to minors was not prohibited before passage of tobacco control legislation in 1996, children had greater access to cigarettes during the period of our study than they do now.

In other countries smoking prevalence among the young generally increases with increasing age. ${ }^{18}{ }^{19}$ However, our study found, alarmingly, that those aged eight years and younger had the highest prevalence of ever-smoking. Our findings are consistent with those of Bilir et al,,$^{15}$ who showed that $13 \%$ of current smokers under the age of 20 started smoking before 11 years of age. They also found that $60 \%$ of the smokers over 50 years of age reported that they started smoking at the age of 21 or above. This demonstrates that the age of smoking initiation has shifted downward towards the age of 10 in Turkey. A number of factors may have contributed to this trend, but the primary cause may have been an increase in the legitimisation of smoking.

In this study, parental smoking was found to be relatively high $(66 \%$ of respondents reported having at least one smoking parent). In addition to parental role modelling, the very high smoking rates among teachers (51\%), journalists (64\%), artists (46\%), physicians (51\%), and sportsmen (35\%) may be influencing children to start smoking. ${ }^{15}$ Even in calendars or on television, it is not uncommon to see photographs showing smoking by Atatürk (the founder of modern Turkey) or by famous politicians, providing children with another source of positive images for smoking.

Contrary to other studies, ${ }^{920}$ our study showed no difference in the recognition rates for cigarette brand names according to smoking status. Cigarette brand identification was mostly related to socioeconomic level; that is, the higher the income, the higher the recognition rate. This could be attributed to more intense exposure of children to tobacco advertising and promotion in communities at higher socioeconomic levels.

Despite the frequent advertising of Colgate, the recognition rate for the Colgate logo was behind that for the Camel and Coke logos. This may be due to the relatively uncommon usage of toothpaste in the homes of children participating in our study. A recent survey in Turkey showed that toothpaste has never been used in $30 \%$ of all homes. ${ }^{21}$

It has been 11 years since McDonald's was introduced in Turkey. ${ }^{22}$ The number of McDonald's restaurants has reached 83. However, the logo was the least recognised among all of the logos used in the study. This could be caused by ineffective advertising or lower consumption of "fast food" among children of primary school age in Turkey. It seems that cultural factors continue to have a strong influence on eating habits at home in Turkey.

A law that was meant to ban cigarette advertising was not put into practice because of disapproval by the former president, who argued that it was against the principles of free trade. The World Health Organisation, however, has advocated a ban on tobacco advertising and promotion. ${ }^{23}$ Banning all forms of tobacco advertising and forbidding the sale of tobacco products to children in Turkey should be seriously considered as part of a smoking prevention policy. Despite the existence of a law which totally bans all types of advertising and promotion, ${ }^{8}$ tobacco companies are constantly finding ways to circumvent the law through indirect cigarette advertising. As noted above, examples include cigarette signs on store fronts, news reports about the Camel 
Adventure Tour and the Turkish rally team supported by Marlboro, and cigarette price announcements in the print media (figures 2 and 3 ).

The health warning currently required on cigarette packets dates back to 1986: "Smoking is harmful to your health". ${ }^{8}$ More effective, rotating health warnings are needed. In addition, the toxicity of existing brands needs to be reduced; currently, most of the domestic brands have a tar yield exceeding $25 \mathrm{mg}$ per cigarette. ${ }^{24}$

The anti-smoking campaign has begun in Turkey. However, considerable progress remains to be made, especially in reducing or eliminating smoking in public spaces. The success of the campaign will depend heavily on the global approach towards this issue, and on control of international cigarette trade.

The authors are grateful to Miss Iman Roushdy (Hammady), $\mathrm{PhD}$ candidate at Harvard University, for her editorial assistance.

1 Akbay M, Karagözoḡlu S. Tide turning for Tekel. Tekel director-general Akbay on stock reduction, new brands, joint ventures. Tekel Dergisi 1996;10:9-11.

2 Kardüz AR. Tekel 2001. Sabah 1994 Aug 19:9.

3 Kluger R. Ashes to ashes: America's hundred-year cigarette war the public health, and the unabashed triumph of Philip Morris. New York: Alfred A Knopf, 1996:727.

4 Anon. Cowboy captures Turkish tobacco market. Milliyet 1998 Feb 26:7.

5 Anon. Public health survey on smoking. PIAR Ltd, 1988

6 Firat D, Hayran M. Cancer statistics in Turkey and in the world (1990-1992). Ankara: Iz Matbaac1l1k, 1995:26.
7 Chapman S. The ethics of tobacco advertising and advertising bans. Br Med Bull 1996;52:121-31.

8 Emri S. New legislation in Turkey. Tobacco Control 1997;6:61.

9 Peters J, Betson CL, Hedley AJ, et al. Recognition of cigarette brand names and logos by young children in Hong Kong. Tobacco Control 1995; 4:150-5.

10 Horasan E, Sezer RE. Cigarette smoking prevalence among grade eight students in Elazig-Turkey, 1993. Turkish $\mathcal{F}$ Smoking Health 1995;2:17-26 (in Turkish).

11 Tümerdem Y, Teko, Ayhan B. Smoking prevalence study in primary schools of a metropolis. 1. An epidemiological study in children from squatter region. Solunum Hastalklarn 1990;1(supp 2):51 (in Turkish).

12 Diamond A Goddard E. Smoking among secondary school children in 1994. London: Her Majesty's Stationery children in

13 Charlton A. Children and smoking: the family circle. $\mathrm{Br} \mathrm{Med}$ Bull 1996;52:90-107.

14 Anon. Smoking prevalence in Istanbul. Milliyet $1988 \mathrm{Feb}$

15 Bilir N, Dagan BG, Emri S, et al. Smoking behavior and attitudes: Ankara-Turkey (in Turkish). Hacettepe Halk

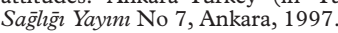

16 Fischer PM, Schwartz MP, Richards JW, et al. Brand logo recognition by children aged 3 to 6 years. $7 A M A$ 1991;266:3145-48

17 Bewley BP, Bland JM, Harris R. Factors associated with the starting of cigarette smoking by primary school children. Br F Prev Soc Med 1974;28:37-44.

18 Meijer B, Branski D, Knol K, et al. Cigarette smoking habits among schoolchildren. Chest 1996;110:921-6.

19 Escobedo LG, Marcus SE, Holtzman D, et al. Sports participation, age at smoking initiation, and risk of smoking among US high school children. $¥ A M A$ 1993; $269: 1391-5$.

20 Chapman S, Fitzgerald B. Brand preference and advertising recall in adolescent smokers: some implication for health promotion. Am F Public Health 1982;72:491-4

21 Süleyman D. Hürriyet 1998 Jan 1:9.

22 Yücebiyik S. McDonald's whooper fighting. Milliyet 1998 Mar 20:10.

23 World Health Organisation. Sponsorship of cultural and sports activities. Press summary. WHO Tobacco Alert Advisory Kit. Geneva: WHO, 1996.

24 Firat D. Tobacco and cancer in Turkey. 7 Environ Pathol Toxicol 1996;15:155-60.

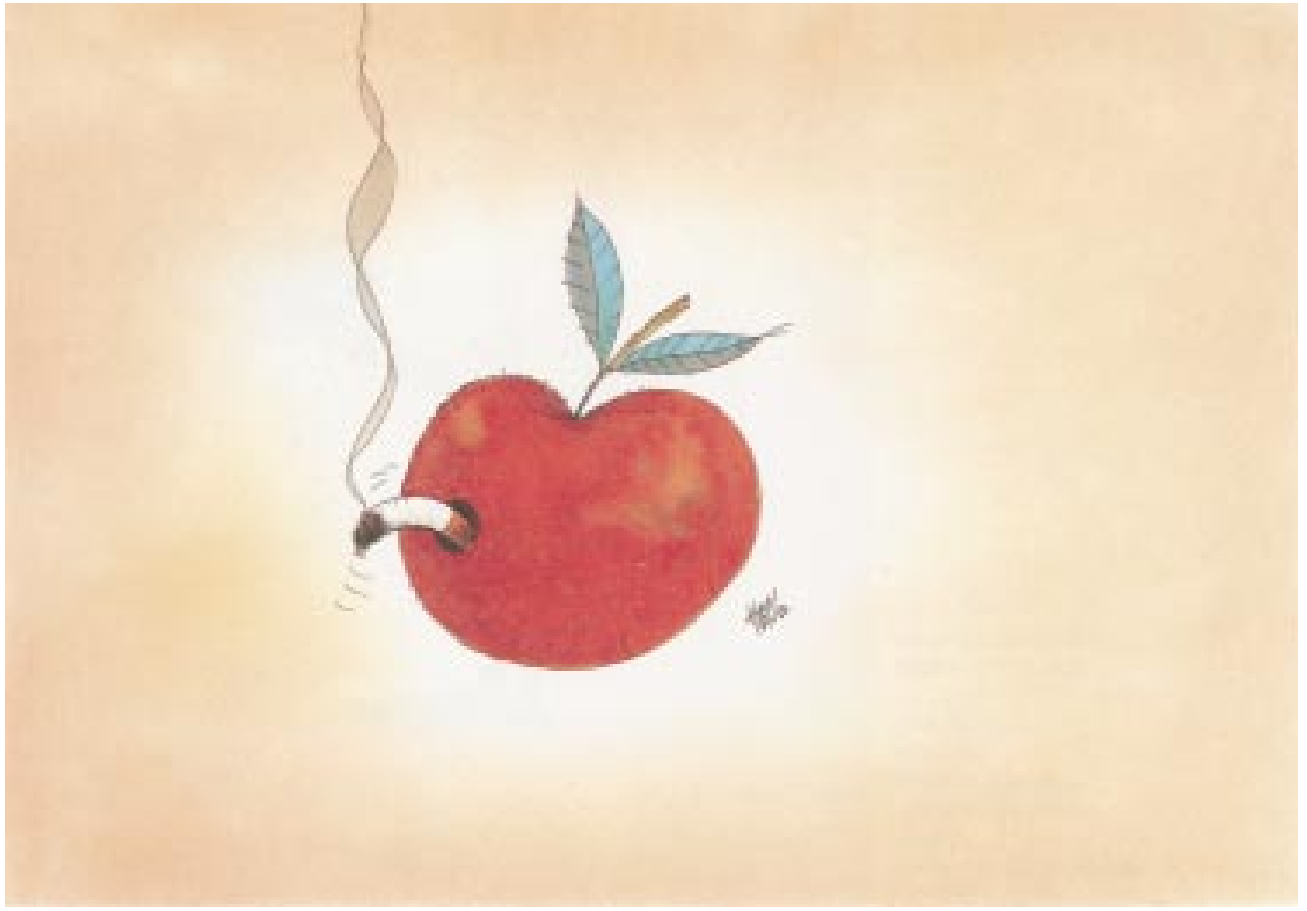

By Kâmil Yavuz (Turkey). 